\title{
A SATISFACTORY FORM OF HIGH RESISTANCE.
}

By G. W. Stewart.

$\mathrm{A}^{\mathrm{n}}$

DISCUSSION ${ }^{1}$ of the measurement of current by means of the steady deflection of an electrometer needle called my attention to the fact that there is an increasing demand for a satisfactory form of a very high resistance. Rutherford, in the above reference, states that Bronson was unable to obtain sufficiently high and yet constant resistances; that tubes of xylol had too great a resistance while special carbon resistances were not sufficiently constant.

The low conductivity of carbon has naturally attracted the attention of those looking for satisfactory forms of high resistances, but the lack of constancy has always been a very great disadvantage. Longden ${ }^{2}$ has published several methods of making carbon resistances which prove to be quite satisfactory, but, as he states, all the resistances increase with the time. Smoke films deposited on glass, hardened by exposure to alcohol vapor, and then covered with shellac varnish, india-rubber varnish or paraffin wax, proved to be the most satisfactory.

This note makes record of a very convenient and satisfactory form of high resistance in which carbon is utilized, and also furnishes data as to its constancy. The use of a transparent lacquer called "Zapon" in the shop of the laboratory, directed my attention to its possible combination with carbon in the formation of a permanent high resistance. The lacquer consists of soluble cotton dissolved in certain mixed solvents, the chief ingredient of which is amyl acetate. When dry, there is left a film of pyroxyline which is elastic, is not subject to ordinary changes in temperature, does not evaporate, does not crack, and is a good insulator. ${ }^{3}$ These

${ }^{1}$ Rutherford's Radioactivity, I906, p. I04.

${ }^{2}$ Longden, Physical Review, I 5, I902, p. 355.

3 The General Electric Company controls a patent (No. 687,5I7) for the use of pyroxyline dissolved in a solution containing amyl acetate as applied to electrical conductors as an insulating material. This method of insulating wire is now in commercial . use (Elec. World, Vol. XLIX., No. I4, April 6, I907, p. 686). 
characteristics are extremely important, and the possession of them by this lacquer is the occasion of this article. It occurred to me that if lampblack were mixed with this lacquer and spread with a brush upon an insulator, a permanent and yet high resistance might be obtained. Experiment has proven this to be the case. The commercial "Germantown" lampblack and the lacquer known as "Zapon $\mathrm{L} "$ " were used in the experiments. The results obtained can be best described by discussing the several points of excellence of such resistances.

Convenience. - As already suggested, the resistance is obtained by spreading the mixture of lampblack and zapon upon an insulating surface. The conductivity of the films thus produced can be easily regulated by the amount of lampblack used and the thickness to which the lacquer is spread with the brush. By trial, I secured a variation in resistance from $3,000 \mathrm{ohms}$ to $3,000,000 \mathrm{ohms}$ with a film approximately $3 \mathrm{~mm}$. long and $2 \mathrm{~mm}$. wide. In order to control the range in constructing high resistances, mixtures with varying proportions of lampblack can be kept on hand. In some experiments, resistances as high as 40,000 megohms are desired. With a film similar to the one just mentioned, it would be possible to secure this enormous resistance by a strip $0.2 \mathrm{~mm}$. wide and 4 meters long. Doubtless films of less conductivity can be secured readily, thus making the length required more easily obtainable.

A further convenience is that the process of making the films is simple and easy of execution, requiring no special apparatus whatever. The forms in which the resistances can be made are unlimited, and can be determined by the purpose for which the resistance is intended. Thus far, I have experimented only with hard rubber as a base for the lacquer, and the different forms in which the rubber is readily obtainable means great convenience in the construction of such resistances. It should be stated that the sample of zapon I have used will not cling very satisfactorily to a very smooth surface, unroughened glass for example.

Permanency. - Films of shellac, india-rubber varnish, paraffin, and no doubt other substances have been proposed as binders for the

1 "Zapon $L$ " is the trade name given by the manufacturers, the Celluloid Zapon Company, Stamford, Conn. 
carbon particles, the object being to make the resistance as permanent as possible. A film of pyroxyline has a decided advantage from the standpoint of permanency, for it will neither crack readily nor deteriorate.

In securing permanency care must be taken to eliminate changes in the contact between the terminals and the film. This is done by making the terminals a part of the base itself. In some of the experiments, this condition was secured by making the terminals of copper plugs screwed into the rubber plate. Longden ${ }^{1}$ solved this difficulty by making the terminals of deposited silver films.

Experiments were made to test the variation of such resistances with time. Two resistances made in January were found to have varied but 3 per cent. five months later. Films of less conductivity do not age so quickly. For example, one of very much less conductivity had a value of 4.13 megohms on May I I, the day following the manufacture; on May I 3 a value of $3.6 \mathrm{I}$ megohms ; on May I 5, a value of 3.45 megohms, on May 20, a value of 3.35 megohms. These figures show a variation which is at first quite large, but which grows smaller quite rapidly.

Doubtless a process of aging by baking would bring such films to a practically steady value at once. Of course a resistance which is composed of carbon particles held in position by a hardened film could in no case be as constant as a metallic resistance. It would therefore be necessary to calibrate constructed resistances from time to time, but with such occasional calibration they would remain sufficiently constant for fairly accurate work.

A variation of the resistance with the impressed voltage would not be surprising. In my first experiments, I found that the resistance decreased with increase of voltage. However, after making the terminals more a part of the base itself, as already suggested, I found the variation to be less than one half of one per cent. with a variation of voltage of I,O00 per cent. In fact, I did not detect any regular variation with voltage at all, for the sensitiveness of the apparatus would permit the detection of a variation no less than that already stated. The observations were made by connecting the resistances in series with a source of voltage and a galvanometer.

$$
{ }^{1} \text { Longden, loc. cit. }
$$


The resistance consisted of a film about $3 \mathrm{~mm}$. long and $2 \mathrm{~mm}$. wide. Readings were taken with films ranging from $100,000 \mathrm{ohms}$ to 3 megohms. In each case the voltage was varied at least $\mathrm{I}, 000$ per cent., the actual values used depending upon the sensitiveness of the galvanometer.

The question as to the variation with voltage is an important one, in as much as in the electrometer method of measuring ionization currents, the voltage employed varies with the current to be measured. The experiments I have performed do not prove that these carbon resistances remain constant at small voltages (O.O I of a volt is sometimes used with a resistance of 30,000 megohms.) From general considerations, however, it would seem highly probable that there would be less, instead of greater, variation at lower voltages. Doubtless this form of resistance would therefore be satisfactory in the measurements of ionization currents. Apparatus with which to prove this point was not at my disposal.

As would be expected there is a variation in these carbon resistances with the temperature. A number of observations were made through small ranges of temperature, and the results show a variation of from O. I to O.I 5 per cent. per degree centigrade. Of course this figure will depend somewhat upon the base employed for the film, and consequently must be determined for each arrangement.

The permanence of the film of pyroxyline, the fact that it can be subjected to ordinary ranges of temperature without cracking or deteriorating, would indicate that properly constructed resistances would give satisfaction for an indefinite time. Furthermore, resistances of a few megohms might easily be enclosed in sealed tubes in order to obviate any variations due to moisture. ${ }^{1}$ It is believed, therefore, that this note suggests a form of high resistance which is both convenient and reasonably permanent, subjected only to very slow changes in resistance with time, and which will prove especially satisfactory where very high resistances of thousands of megohms are desired.

Physical LABORATOKy, UNIVERSity OF NORTH DAKOTA.

1 Since writing the above, I have found that these resistances increase somewhat with increase in humidity. Whether this is due to the occlusion of water vapor by the carbon or to the swelling of the pyroxyline film, has not been ascertained. 